\title{
Rancang Bangun Sistem Informasi Kampus Hijau Berbasis Web Pada JSN (Jaringan Sensor Nirkabel)
}

\author{
Aulia Medisina Ramadhan ${ }^{1)}$, Oky Dwi Nurhayati ${ }^{2)}$, Eko Didik Widianto ${ }^{2)}$ \\ Jurusan Sistem Komputer, Fakultas Teknik, Universitas Diponegoro \\ Jl. Prof. Sudharto, Tembalang, Semarang, Indonesia
}

\begin{abstract}
Lingkungan merupakan masalah bersama yang membutuhkan sinergi semua lapisan masyarakat, termasuk civitas akademika. Oleh karena itu, kampus hijau turut andil dalam upaya pengelolaan lingkungan. Pemantauan lingkungan berbasis teknologi dapat membantu pemerhati lingkungan untuk memantau area kampus. Alat pemantauan lingkungan dapat berupa sensor pendeteksi konsentrasi gas $\mathrm{CO}, \mathrm{NO}_{2}$, kepadatan partikel debu, suhu, kelembaban udara dan intensitas cahaya. Agar data sensor dapat diketahui oleh seluruh pemerhati lingkungan yang berada di mana saja, maka dibutuhkan wadah yang mampu menyajikan data sensor secara realtime.

Sistem Informasi Kampus Hijau dibangun dengan menggunakan bahasa pemrograman PHP dan MySQL sebagai penyimpanannya. Metode perangkat lunak yang digunakan adalah waterfall yang terdiri dari analisis kebutuhan, desain, pengkodean, pengujian dan pemeliharaan. Pengujian fungsional yang dilakukan menggunakan metode blackbox.

Hasil yang diharapkan dari Sistem Informasi Kampus Hijau ini adalah terciptanya sistem informasi yang dapat menyajikan data lingkungan yang dihasilkan oleh sensor pendeteksi secara realtime.
\end{abstract}

Kata kunci : Kampus Hijau, Teknologi dan Informasi

\section{Pendahuluan}

$\mathrm{S}$ aat ini, isu lingkungan cukup sering diperbincangkan. Semakin menipisnya lapisan ozon, akan membawa banyak dampak negatif terhadap lingkungan serta kurangnya informasi mengenai lingkungan yang informatif pada area kampus. Hal tersebut menggugah para pemangku kepentingan kampus untuk turut andil dalam memantau kondisi lingkungan area kampus dengan mengangkat kampus hijau. Salah satu kampus yang telah menerapkan green campus ialah Universitas Indonesia (UI) yang merupakan peringkat 33 pada UI Green Metric World University Ranking. ${ }^{[1]}$ Pada Universitas Indonesia, memiliki konsep untuk menangkal berkembangnya global warming ke dalam kampus berupa penyediaan jalur sepeda untuk membuat udara kampus lebih segar lewat pengurangan kendaraan bermotor di dalam kampus. ${ }^{[2]}$

Pada kasus kampus hijau untuk menunjang pemantauan kondisi lingkungan yang dapat dilakukan setiap waktu, diperlukan peralatan untuk memantau beberapa area pada kampus dan mendata kondisi lingkungan kampus agar lingkungan kampus dapat terjaga karena kenyamanan lingkungan sangat penting, selain itu kenyamanan juga bisa mempengaruhi keadaan psikologis seseorang. Hal yang mempengaruhi kondisi kenyamanan sebuah lingkungan adalah udara. Oleh karena itu perlu adanya pengawasan dan penilaian mengenai keadaan ini agar tercapai lingkungan yang nyaman dan menyehatkan, kondisi lingkungan yang perlu didata diantaranya adalah konsentrasi gas $\mathrm{CO}, \mathrm{NO}_{2}$, kepadatan partikel debu, suhu, kelembaban udara dan intensitas cahaya pada beberapa titik yang terletak di area kampus dikarenakan kondisi lingkungan pada beberapa titik di area kampus tersebut berbeda. Pemantauan lingkungan kampus tersebut menggunakan beberapa sensor lingkungan yang berkaitan serta sebuah server pengelola data untuk menyajikan dan mengolah data yang akan terhubung menggunakan teknologi nirkabel.

Alat pemantauan pencemaran udara telah ada sebelumnya yang salah satunya terpasang di kota Surabaya, alat ini hanya berupa display dengan menggunakan layar $L C D$ dan belum memiliki sistem informasi yang dapat diakses melalui web. Surabaya memiliki 2 buah alat pemantauan pencemaran udara yang mendeteksi $\mathrm{PM}, \mathrm{SO}_{2}$, $\mathrm{CO}, \mathrm{O}_{2}$ dan $\mathrm{NO}_{2}{ }^{[3]}$

\section{Metodologi Penelitian}

Metodologi penelitian pada sistem informasi ini menggunakan model waterfall yang pengerjaan dari suatu sistem dilakukan secara berurutan atau secara linear yang memiliki enam tahap yang berbeda yaitu: ${ }^{[6]}$ Analisa kebutuhan, Sistem dapat menampilkan data lingkungan secara realtime berupa karbon monoksida, nitrogen dioksida, partikel debu, suhu, kelembaban udara, intensitas cahaya dan kelembaban tanah.sistem juga memiliki fasilitas login untuk admin yang digunakan untuk mengelola daftar sensor. Desain pada sistem ini menggambarkan interface sistem dan alur kerja sistem dengan use case diagram, activity diagram, sequence diagram dan entity relationship diagram. Implementasi sistem ini menggunakan framework codeigniter dengan bahasa pemrograman PHP dan MySQL versi 5.5.25. Pengujian sistem ini menggunakan pengujian blackbox untuk menguji semua fungsi pada sistem. Pemeliharaan, Perangkat lunak yang sudah disampaikan kepada pelanggan pasti akan mengalami perubahan karena perangkat lunak harus menyesuaikan dengan lingkungan baru

\section{Perancangan Sistem}

Perancangan sistem menggunakan beberapa diagram untuk menggambarkan alur kerja sistem serta interaksi sistem dengan pengguna.

Use case mendeskripsikan sebuah interaksi antara satu atau lebih aktor dengan sistem informasi yang akan dibuat. ${ }^{[4]}$ Use case diagram pada sistem ini memiliki 3 aktor yaitu pengunjung, admin dan sensor seperti pada Gambar 1 berikut ini. 


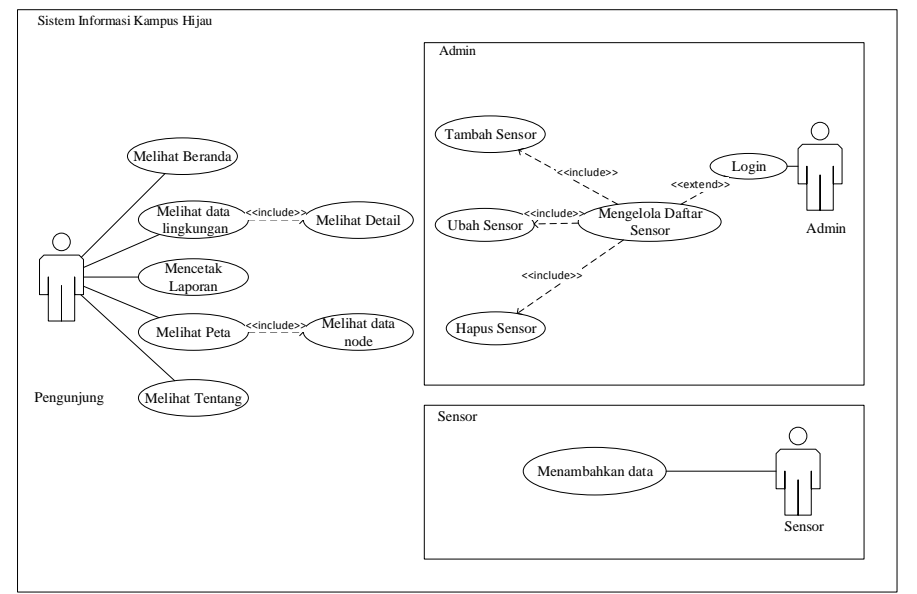

Gambar 1. Use Case Diagram

Activity diagram digunakan untuk menggambarkan aktivitas dari sebuah sistem yang ada pada perangkat lunak. ${ }^{[4]}$ Gambar 2 merupakan activity diagram beranda. Gambar 3 activity diagram login. Gambar 4 merupakan activity diagram data lingkungan. Gambar 5 merupakan activity diagram detail sensor. Gambar 6 merupakan activity diagram buat laporan. Gambar 7 merupakan activity diagram lihat peta. Gambar 8 merupakan activity diagram lihat node peta. Gambar 9 merupakan activity diagram daftar sensor. Gambar 10 merupakan activity diagram hapus daftar sensor. Gambar 11 merupakan activity diagram ubah data. Gambar 12 merupakan activity diagram tambah sensor. Gambar 13 merupakan activity diagram tambah data. Gambar 14 merupakan activity diagram tentang.

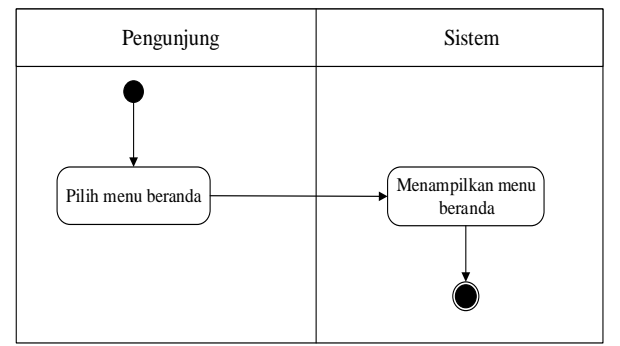

Gambar 2. Activity diagram beranda

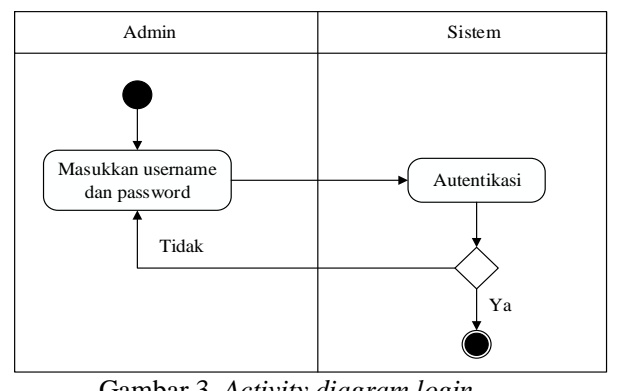

Gambar 3. Activity diagram login

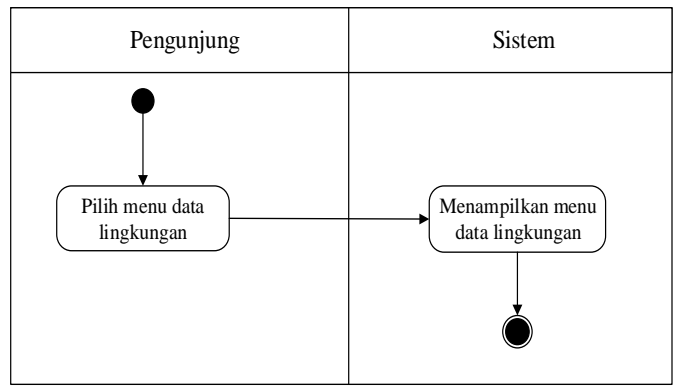

Gambar 4. Activity diagram data lingkungan

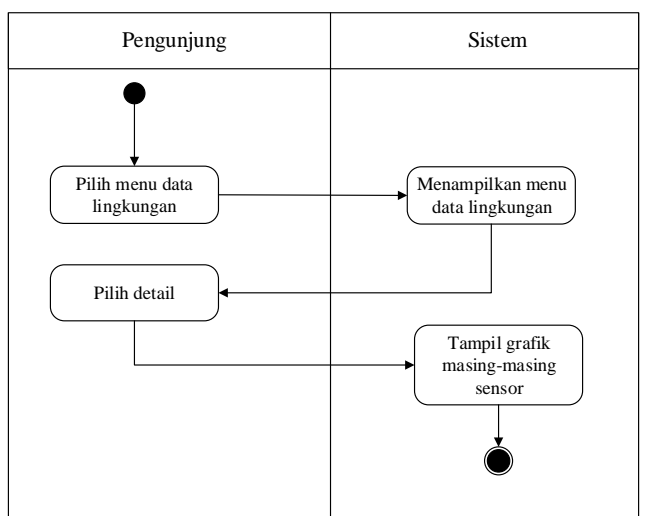

Gambar 5. Activity diagram detail sensor

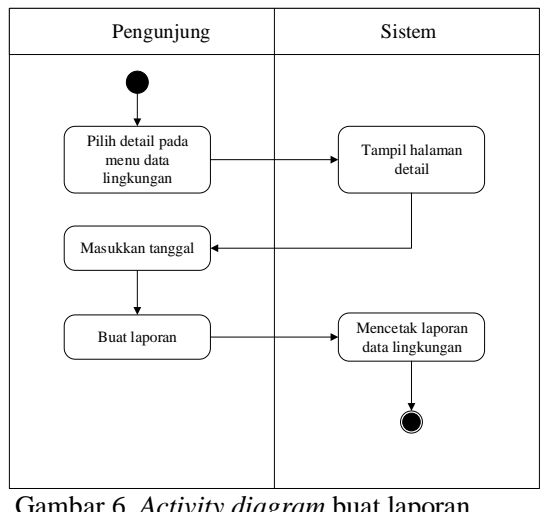

Gambar 6. Activity diagram buat laporan

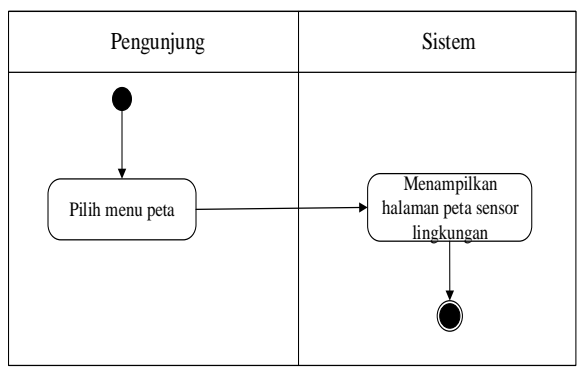

Gambar 7. Activity diagram lihat peta 

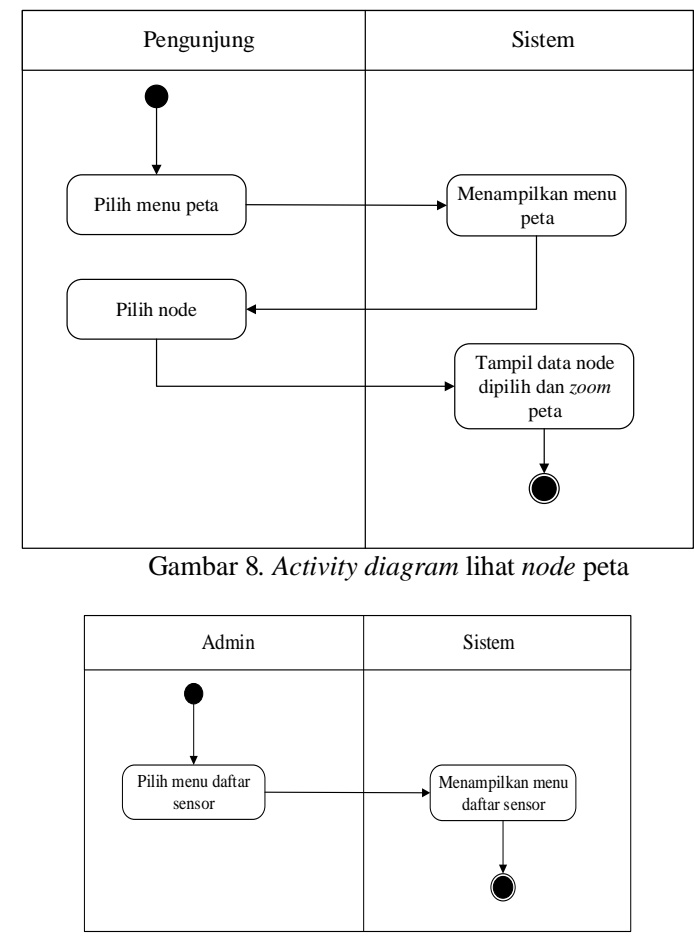

Gambar 9. Activity diagram daftar sensor

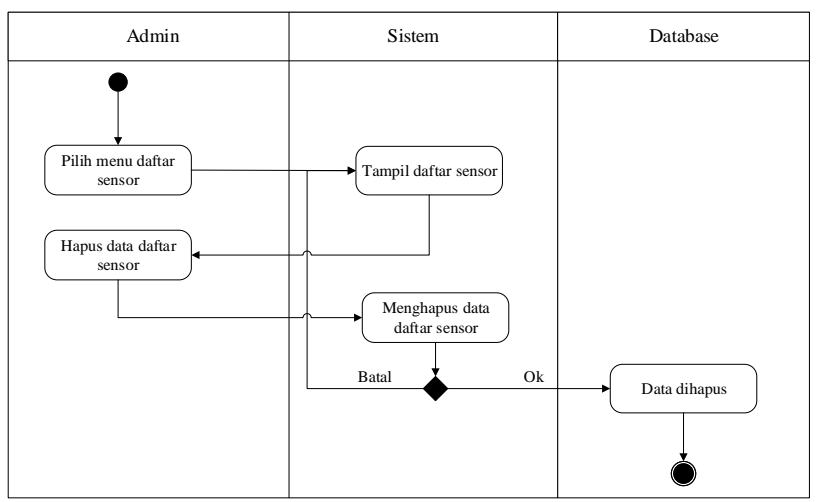

Gambar 10. Activity diagram hapus daftar sensor

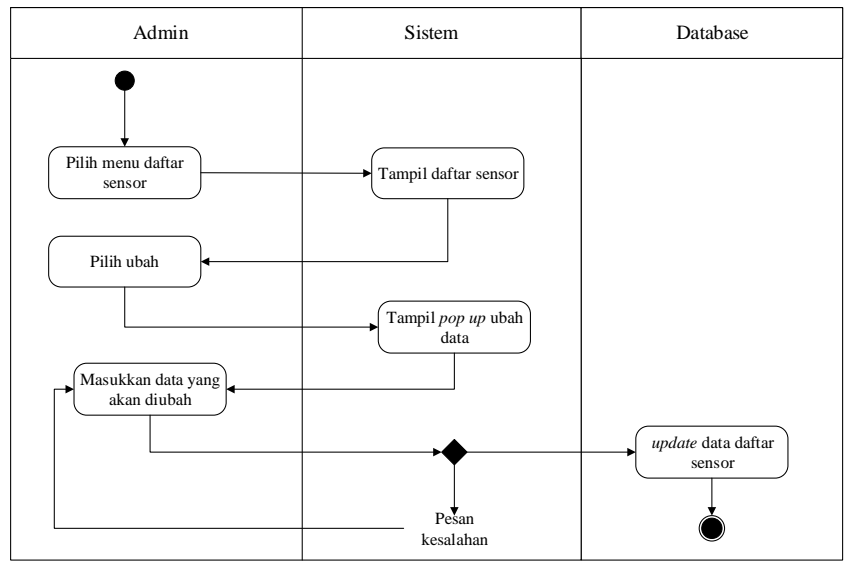

Gambar 11. Activity diagram ubah data

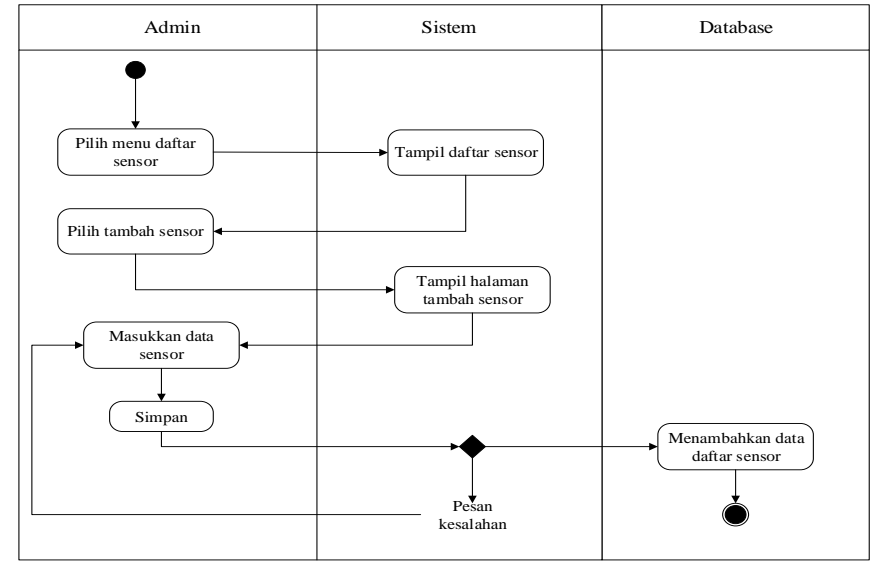

Gambar 12. Activity diagram tambah sensor

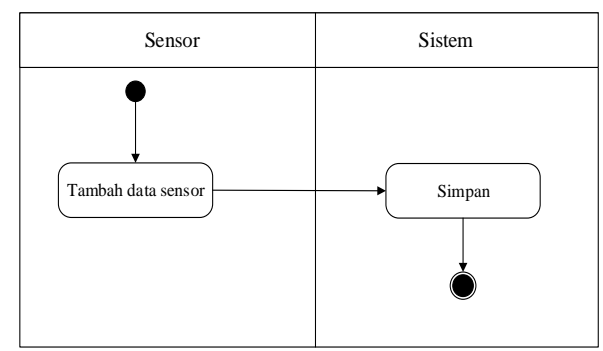

Gambar 13. Activity diagram tambah data

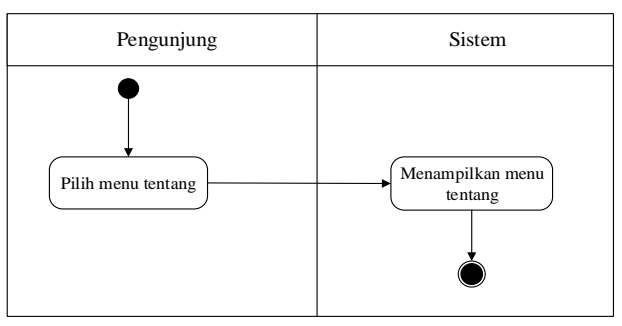

Gambar 14. Activity diagram tentang

Sequence diagram merupakan gambaran tahapan yang dilakukan untuk menghasilkan sesuatu sesuai dengan use case. ${ }^{[5]}$ Gambar 15 merupakan sequence diagram beranda. Gambar 16 merupakan sequence diagram login. Gambar 17 adalah Sequence diagram data lingkungan. Gambar 18 adalah Sequence diagram detail sensor. Gambar 19 adalah Sequence diagram buat laporan. Gambar 20 adalah Sequence diagram daftar sensor. Gambar 21 merupakan sequence diagram hapus daftar sensor. Gambar 22 merupakan sequence diagram ubah daftar sensor. Gambar 23 merupakan sequence diagram tambah sensor. Gambar 24 merupakan sequence diagram lihat peta. Gambar 25 merupakan sequence diagram halaman peta. Gambar 26 merupakan sequence diagram tambah data.

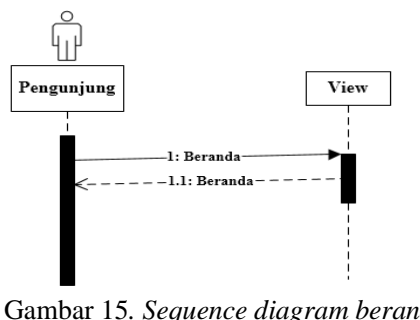




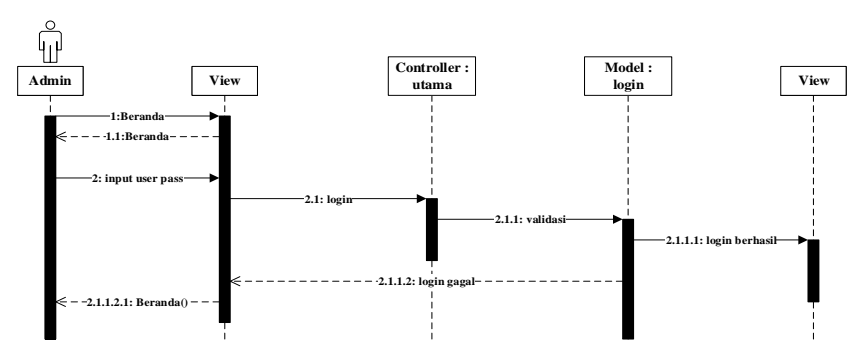

Gambar 16. Sequence diagram login

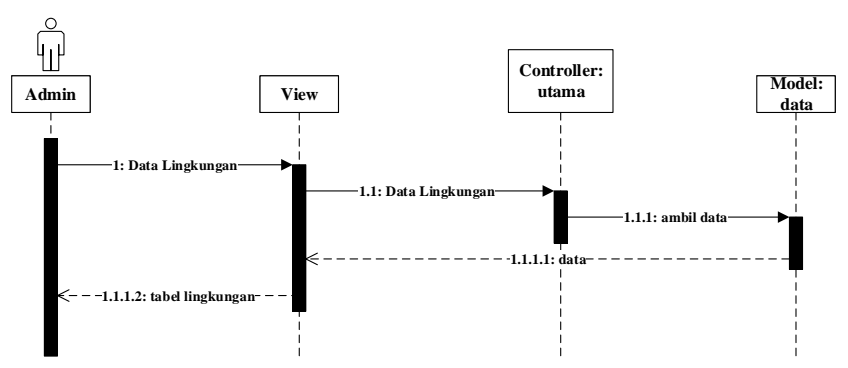

Gambar 17. Sequence diagram data lingkungan

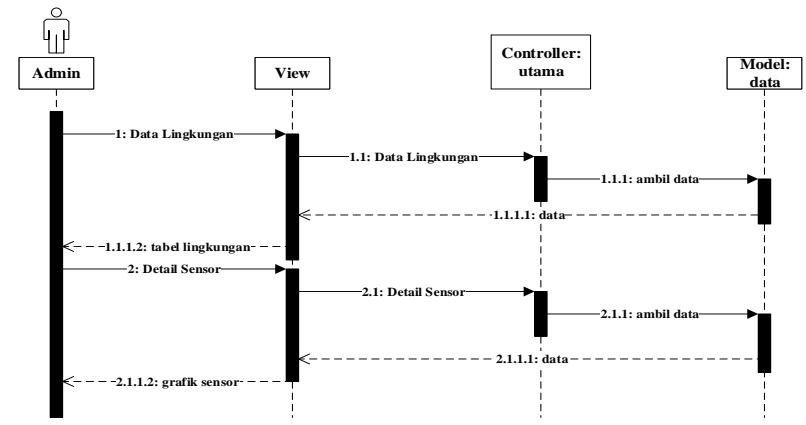

Gambar 18. Sequence diagram detail sensor

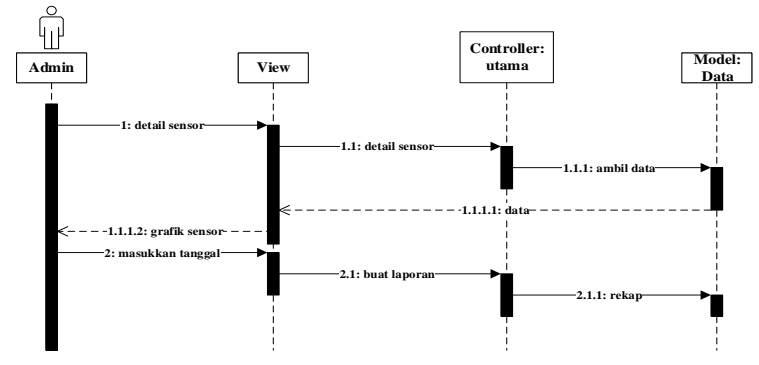

Gambar 19. Sequence diagram buat laporan

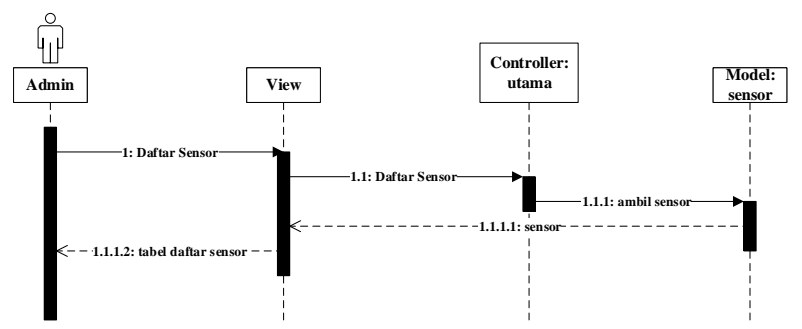

Gambar 20. Sequence diagram daftar sensor

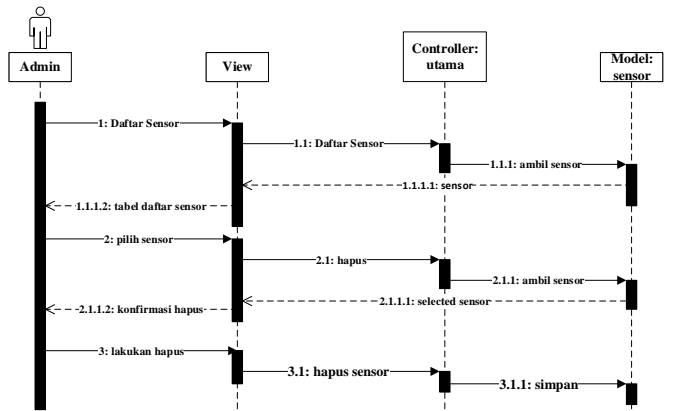

Gambar 21. Sequence diagram hapus daftar sensor

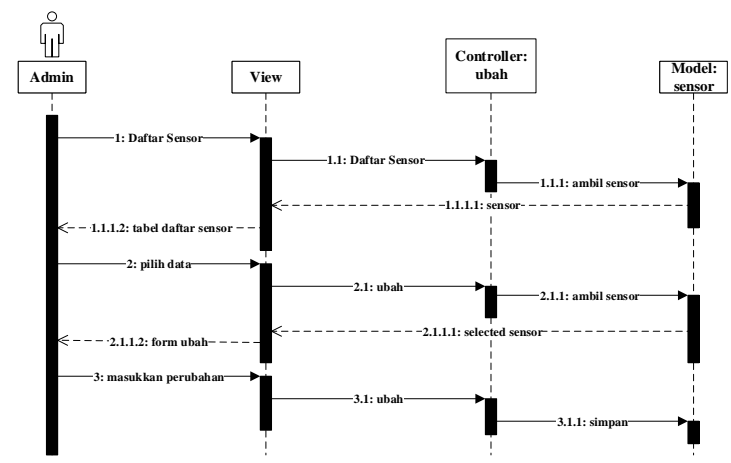

Gambar 22. Sequence diagram ubah daftar sensor

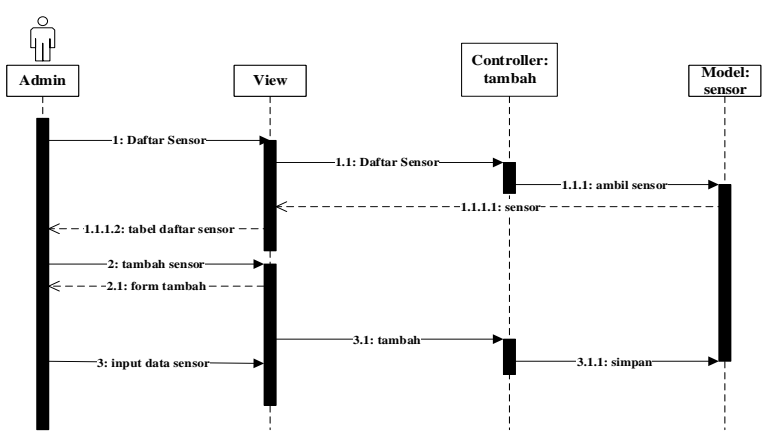

Gambar 23. Sequence diagram tambah sensor

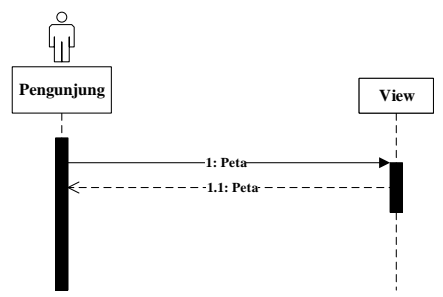

Gambar 24. Sequence diagram lihat peta

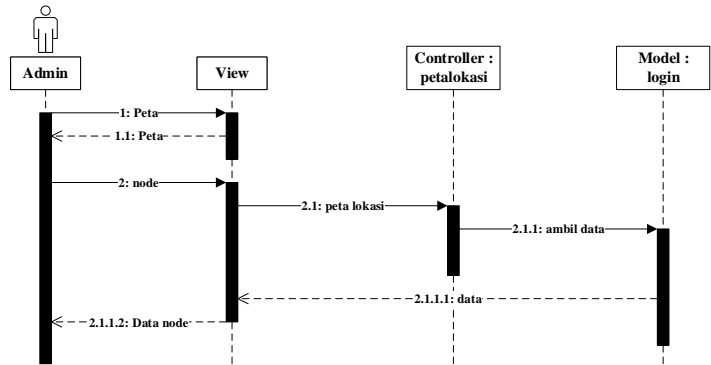

Gambar 25. Sequence diagram halaman peta 


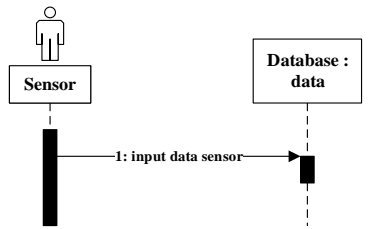

Gambar 26. Sequence diagram tambah data

Perancangan basis data pada sistem ini menggunakan Entity Relationship Diagram (ERD). Gambar 27 merupakan ERD pada perancangan sistem ini.

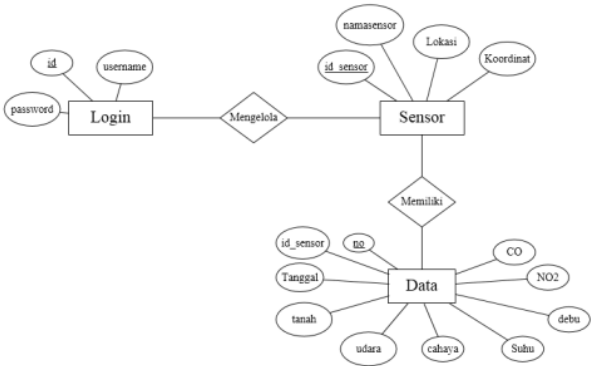

Gambar 27. Entity Relationship Diagram

Perancangan antarmuka atau tampilan sangat diperlukan untuk memberikan suatu gambaran serta penjelasan dari setiap proses. Gambar 28 merupakan halaman utama aplikasi. Gambar 29 merupakan tampilan data lingkungan admin. Gambar 30 merupakan tampilan data lingkungan admin. Gambar 31 merupaan tampilan grafik setiap parameter. Gambar 32 merupakan halaman daftar sensor. Gambar 33 merupakan halaman laporan excel. Gambar 34 menunjukkan tampilan pop up ubah sensor. Gambar 35 menunjukkan tampilan tambah data sensor. Gambar 36 merupakan tampilan peta sensor lingkungan. Gambar 37 merupakan tampilan halaman tentang.

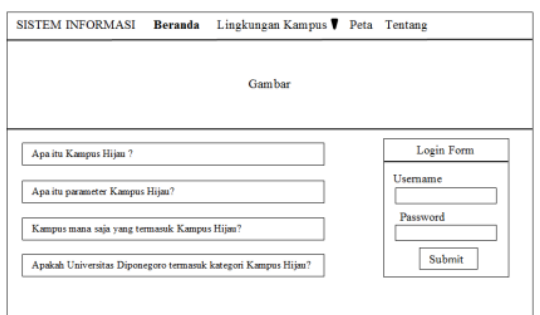

Gambar 28. Halaman beranda

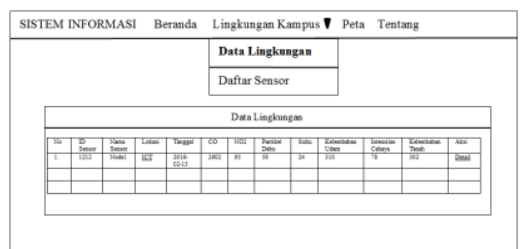

Gambar 29. Halaman data lingkungan admin

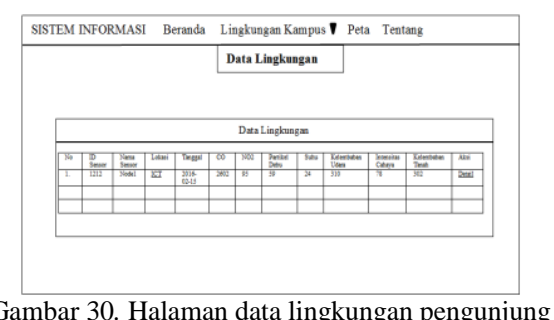

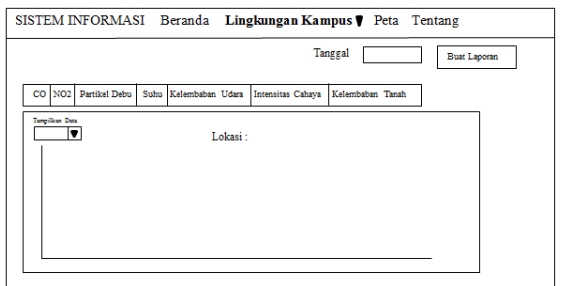

Gambar 31. Halaman detail sensor lingkungan

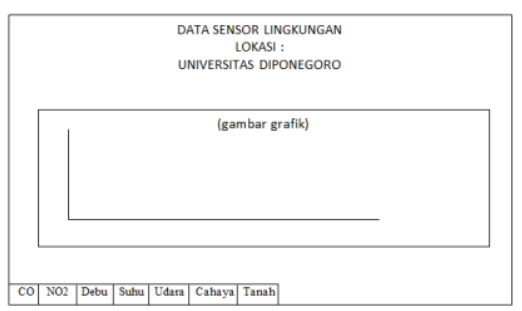

Gambar 32. Halaman laporan

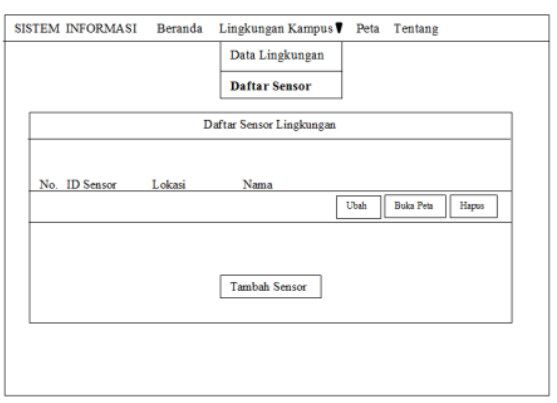

Gambar 33. Halaman daftar sensor untuk admin

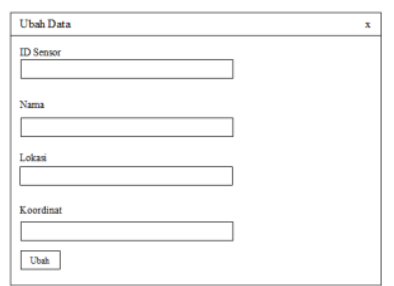

Gambar 34. Halaman ubah daftar sensor

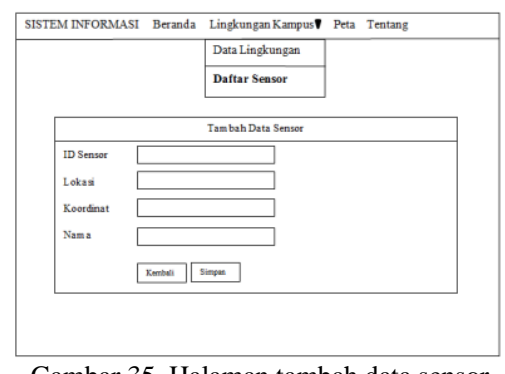

Gambar 35. Halaman tambah data sensor

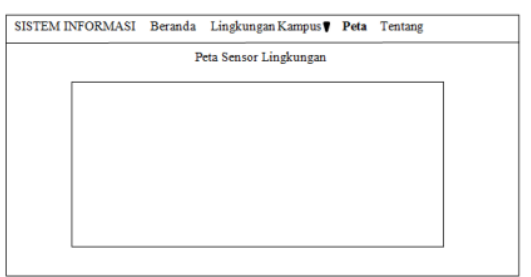

Gambar 36. Halaman peta 


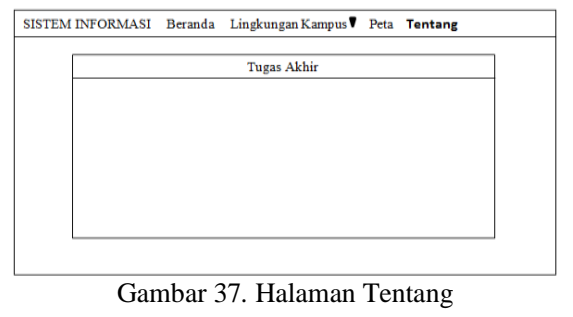

IV. IMPLEMENTASI DAN PENGUJIAN SISTEM

Implementasi program merupakan tahapan mengimplementasikan perancangan yang telah dibuat ke dalam kode pemrograman. Berikut merupakan view halaman beranda pada Gambar 38. Gambar 39 merupakan view halaman data lingkungan. Gambar 40 merupakan view halaman detail sensor. Berikut merupakan view halaman laporan seperti yang ditunjukkan pada Gambar 41. Gambar 42 merupakan view halaman daftar sensor. Gambar 43 merupakan view halaman tambah sensor. Gambar 44 merupakan view halaman ubah data. Gambar 45 merupakan view halaman peta. Gambar 46 merupakan view halaman tentang.
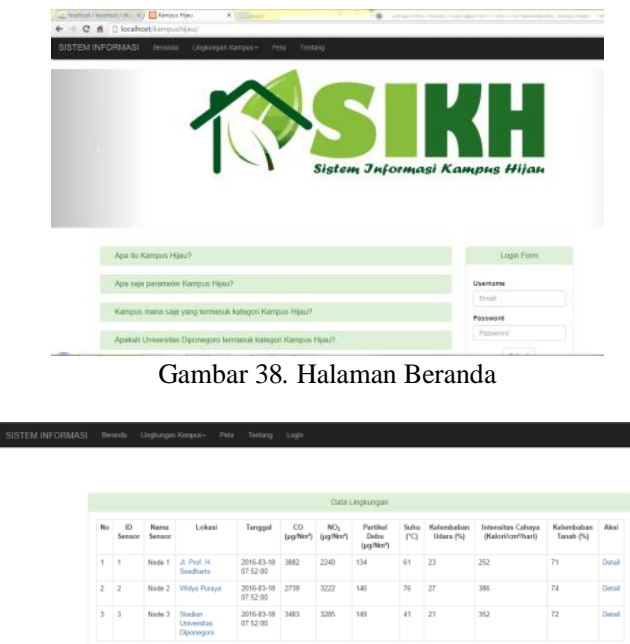

Gambar 39. Halaman Data lingkungan

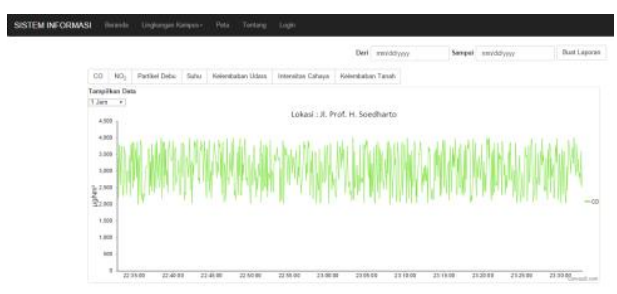

Gambar 40. Halaman Detail Sensor

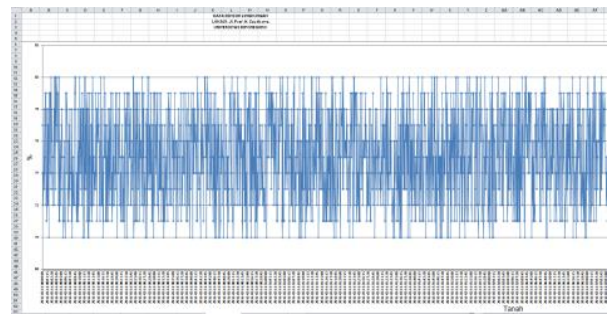

Gambar 41. Halaman Laporan

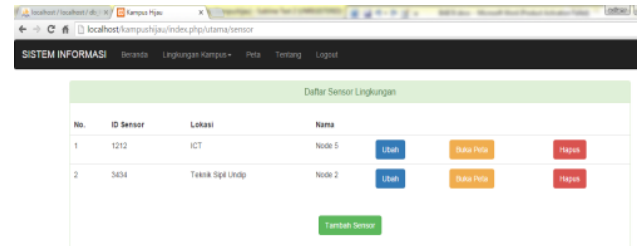

Gambar 42. Halaman Daftar Sensor

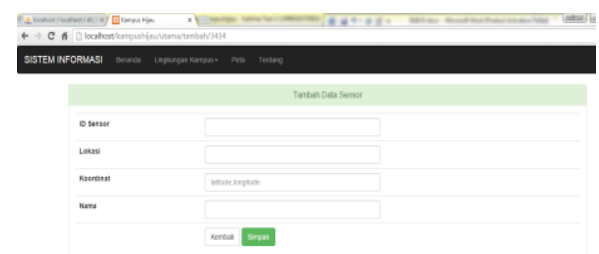

Gambar 43. Halaman Tambah Sensor

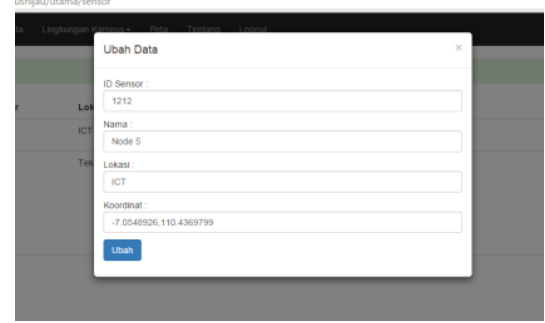

Gambar 44. Halaman Ubah Data

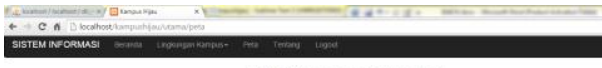

Peta Sensor Lingkungan

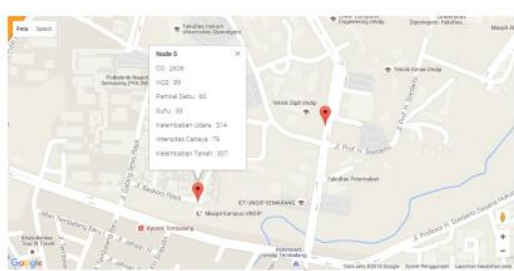

Gambar 45. Halaman peta

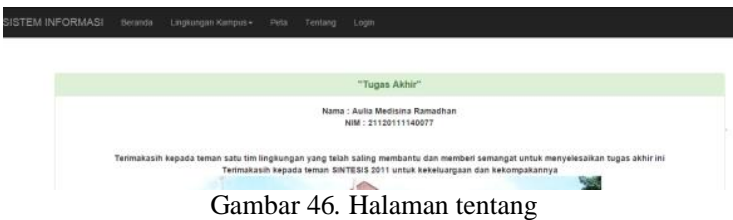

Pengujian digunakan untuk menguji beberapa fungsi yang ada pada sistem informasi. metode pengujian yang digunakan yaitu black box dengan bantuan event pada MySQL seperti pada Gambar 47 untuk memasukkan data setiap 5 detik. Tabel 1 merupakan pengujian halaman login. Tabel 2 merupakan pengujian halaman data lingkungan. Tabel 3 merupakan pengujian halaman tambah sensor. Tabel 4 merupakan pengujian halaman ubah sensor. Tabel 5 merupakan pengujian halaman detail sensor. Tabel 6 merupakan pengujian buat laporan. Tabel 7 merupakan pengujian halaman daftar sensor. Tabel 8 merupakan pengujian pada halaman peta. Tabel 9 merupakan pengujian halaman tentang. 


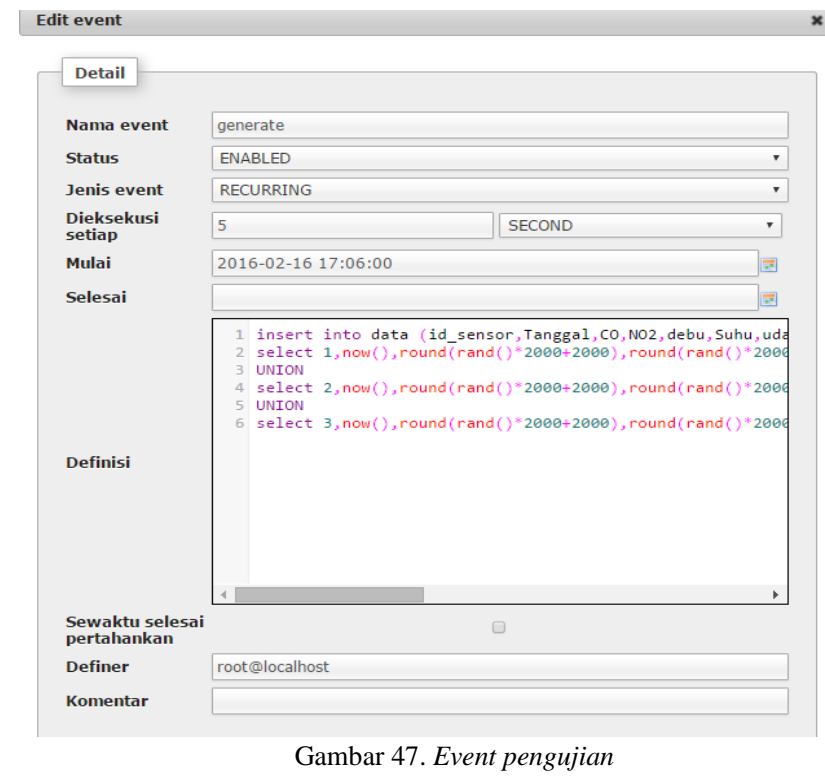

Tabel 1. Pengujian halaman login

\begin{tabular}{|c|c|c|c|}
\hline $\begin{array}{c}\text { Nama } \\
\text { Pengujian }\end{array}$ & $\begin{array}{c}\text { Bentuk } \\
\text { Pengujian }\end{array}$ & Hasil yang Diharapkan & Hasil Pengujian \\
\hline $\begin{array}{c}\text { Pengujian } \\
\text { fungsi } \\
\text { login. }\end{array}$ & $\begin{array}{c}\text { Memasukkan } \\
\text { username dan } \\
\text { password } \\
\text { yang benar }\end{array}$ & $\begin{array}{c}\text { Muncul halaman } \\
\text { beranda dan menu } \\
\text { daftar sensor yang } \\
\text { hanya dapat diakses } \\
\text { oleh Admin yang } \\
\text { melakukan login. }\end{array}$ & Berhasil \\
& $\begin{array}{c}\text { Memasukkan } \\
\text { username dan } \\
\text { password } \\
\text { yang benar }\end{array}$ & $\begin{array}{c}\text { Tampil notifikasi } \\
\text { "Anda berhasil login, } \\
\text { Selamat Datang!" }\end{array}$ & Berhasil \\
& $\begin{array}{c}\text { Memasukkan } \\
\text { username dan } \\
\text { password } \\
\text { yang salah }\end{array}$ & $\begin{array}{c}\text { Tampil pemberitahuan } \\
\text { "Peringatan! username } \\
\text { atau password tidak } \\
\text { cocok" }\end{array}$ & \\
\cline { 2 - 4 } & $\begin{array}{c}\text { Tidak } \\
\text { Memasukkan } \\
\text { username dan } \\
\text { password }\end{array}$ & $\begin{array}{c}\text { Tampil pemberitahuan } \\
\text { "Peringatan! username } \\
\text { atau password tidak } \\
\text { boleh kosong" }\end{array}$ & \\
\hline
\end{tabular}

Tabel 2. Pengujian halaman data lingkungan

\begin{tabular}{|c|c|c|c|}
\hline $\begin{array}{c}\text { Nama } \\
\text { Pengujian }\end{array}$ & Bentuk Pengujian & $\begin{array}{l}\text { Hasil yang } \\
\text { Diharapkan }\end{array}$ & $\begin{array}{c}\text { Hasil } \\
\text { Pengujian }\end{array}$ \\
\hline $\begin{array}{c}\text { Pengujian } \\
\text { tampilan data } \\
\text { ingkungan } \\
\text { secara } \\
\text { realtime } \\
\text { dengan input } \\
\text { dari } \\
\text { generator } \\
\end{array}$ & $\begin{array}{c}\text { Mengaktifkan } \\
\text { generator pada } \\
\text { database kemudian } \\
\text { pilih menu data } \\
\text { lingkungan untuk } \\
\text { melihat data masuk } \\
\text { dari generator }\end{array}$ & $\begin{array}{c}\text { Data berubah } \\
\text { secara otomatis } \\
\text { berdasarkan } \\
\text { data yang } \\
\text { masuk tanpa } \\
\text { harus } \\
\text { melakukan } \\
\text { refresh } \\
\end{array}$ & Berhasil \\
\hline $\begin{array}{l}\text { Pengujian } \\
\text { link detail } \\
\text { sensor }\end{array}$ & $\begin{array}{l}\text { Pilih detail pada } \\
\text { kolom aksi di } \\
\text { halaman data } \\
\text { lingkungan }\end{array}$ & $\begin{array}{c}\text { Menampilkan } \\
\text { halaman detail } \\
\text { sensor yang } \\
\text { berupa grafik } \\
\text { setiap parameter }\end{array}$ & Berhasil \\
\hline $\begin{array}{l}\text { Pengujian } \\
\text { link lokasi }\end{array}$ & $\begin{array}{l}\text { Pilih nama lokasi } \\
\text { pada kolom lokasi di } \\
\text { halaman data } \\
\text { lingkungan }\end{array}$ & $\begin{array}{l}\text { Menampilkan } \\
\text { lokasi dengan } \\
\text { node pada } \\
\text { halaman peta }\end{array}$ & Berhasil \\
\hline $\begin{array}{c}\text { Pengujian } \\
\text { timeout }\end{array}$ & $\begin{array}{c}\text { Data yang } \\
\text { dimasukkan sama } \\
\text { selama } 30 \text { menit } \\
\text { yang berjumlah } 360 \\
\text { baris. }\end{array}$ & $\begin{array}{c}\text { Sensor akan } \\
\text { dideteksi tidak } \\
\text { aktif dan akan } \\
\text { Tampil tulisan } \\
\text { "Tidak Aktif" }\end{array}$ & Berhasil \\
\hline
\end{tabular}

\begin{tabular}{|l|l|c|c|}
\hline & pada tabel & \\
sensor yang & tidak aktif \\
tersebut & \\
\hline
\end{tabular}

Tabel 3. Pengujian tambah sensor

\begin{tabular}{|c|c|c|c|}
\hline $\begin{array}{c}\text { Nama } \\
\text { Pengujian }\end{array}$ & Bentuk Pengujian & $\begin{array}{c}\text { Hasil yang } \\
\text { Diharapkan }\end{array}$ & $\begin{array}{c}\text { Hasil } \\
\text { Pengujian }\end{array}$ \\
\hline $\begin{array}{c}\text { Pengujian } \\
\text { tampilan } \\
\text { tambah } \\
\text { sensor }\end{array}$ & $\begin{array}{c}\text { Memilih tambah sensor } \\
\text { pada halaman daftar } \\
\text { sensor. }\end{array}$ & $\begin{array}{c}\text { Menampilkan } \\
\text { form tambah } \\
\text { sensor }\end{array}$ & Berhasil \\
\hline $\begin{array}{c}\text { Pengujian } \\
\text { tambah } \\
\text { data }\end{array}$ & $\begin{array}{c}\text { Memasukkan data sensor } \\
\text { dengan benar secara } \\
\text { keseluruhan ke dalam form } \\
\text { tambah sensor dan tekan } \\
\text { tombol simpan }\end{array}$ & $\begin{array}{c}\text { Data akan } \\
\text { tersimpan dan } \\
\text { masuk ke } \\
\text { dalam basis } \\
\text { data. }\end{array}$ & Berhasil \\
\hline $\begin{array}{c}\text { Pengujian } \\
\text { alert } \\
\text { peringatan } \\
\text { pada form }\end{array}$ & $\begin{array}{c}\text { Tidak memasukkan data } \\
\text { pada form lalu klik simpan. }\end{array}$ & $\begin{array}{c}\text { Tampil alert } \\
\text { data kosong } \\
\text { dan harus diisi }\end{array}$ & Berhasil \\
\end{tabular}

Tabel 4. Pengujian halaman ubah sensor

\begin{tabular}{|c|c|c|c|}
\hline $\begin{array}{c}\text { Nama } \\
\text { Pengujian }\end{array}$ & Bentuk Pengujian & $\begin{array}{l}\text { Hasil yang } \\
\text { Diharapkan }\end{array}$ & $\begin{array}{c}\text { Hasil } \\
\text { Pengujian }\end{array}$ \\
\hline $\begin{array}{l}\text { Pengujian } \\
\text { tampilan ubah } \\
\text { sensor } \\
\end{array}$ & $\begin{array}{l}\text { Memilih ubah sensor } \\
\text { pada halaman daftar } \\
\text { sensor. }\end{array}$ & $\begin{array}{c}\text { Menampilkan } \\
\text { pop up } u \text { bah } \\
\text { sensor }\end{array}$ & Berhasil \\
\hline $\begin{array}{l}\text { Pengujian } \\
\text { menambahka } \\
\text { n data }\end{array}$ & $\begin{array}{l}\text { Memasukkan data sensor } \\
\text { dengan benar secara } \\
\text { keseluruhan ke dalam } \\
\text { form tambah sensor dan } \\
\text { tekan tombol simpan }\end{array}$ & $\begin{array}{c}\text { Data akan } \\
\text { tersimpan dan } \\
\text { masuk ke } \\
\text { dalam basis } \\
\text { data. }\end{array}$ & Berhasil \\
\hline $\begin{array}{l}\text { Pengujian } \\
\text { menyimpan } \\
\text { data yang } \\
\text { kosong }\end{array}$ & $\begin{array}{c}\text { Mengubah dengan } \\
\text { menghapus salah satu } \\
\text { data pada form ubah dan } \\
\text { simpan }\end{array}$ & $\begin{array}{c}\text { Tampil } \\
\text { pemberitahuan } \\
\text { data tidak } \\
\text { boleh kosong. }\end{array}$ & Berhasil \\
\hline
\end{tabular}

Tabel 5. Pengujian halaman detail sensor

\begin{tabular}{|c|c|c|c|}
\hline $\begin{array}{c}\text { Nama } \\
\text { Pengujian }\end{array}$ & Bentuk Pengujian & $\begin{array}{c}\text { Hasil yang } \\
\text { Diharapkan }\end{array}$ & $\begin{array}{c}\text { Hasil } \\
\text { Pengujian }\end{array}$ \\
\hline $\begin{array}{c}\text { Pengujian } \\
\text { tampilan grafik } \\
\text { CO }\end{array}$ & $\begin{array}{c}\text { Mengaktifkan } \\
\text { generator pada } \\
\text { database, kemudian } \\
\text { memilih CO pada } \\
\text { halaman detail } \\
\text { sensor }\end{array}$ & $\begin{array}{c}\text { Menampilkan } \\
\text { grafik CO yang } \\
\text { akan otomatis } \\
\text { refresh setiap } 5 \\
\text { detik }\end{array}$ & Berhasil \\
\hline $\begin{array}{c}\text { Pengujian } \\
\text { tampilan grafik } \\
\mathrm{NO}_{2}\end{array}$ & $\begin{array}{l}\text { Mengaktifkan } \\
\text { generator pada } \\
\text { database, kemudian } \\
\text { memilih } \mathrm{NO}_{2} \text { pada } \\
\text { halaman detail } \\
\text { sensor }\end{array}$ & $\begin{array}{l}\text { Menampilkan } \\
\text { grafik } \mathrm{NO}_{2} \\
\text { yang akan } \\
\text { otomatis } \\
\text { refresh setiap 5 } \\
\text { detik }\end{array}$ & Berhasil \\
\hline $\begin{array}{c}\text { Pengujian } \\
\text { tampilan grafik } \\
\text { Partikel Debu }\end{array}$ & $\begin{array}{c}\text { Mengaktifkan } \\
\text { generator pada } \\
\text { database, kemudian } \\
\text { memilih Partikel } \\
\text { Debu pada halaman } \\
\text { detail sensor } \\
\end{array}$ & $\begin{array}{c}\text { Menampilkan } \\
\text { grafik Partikel } \\
\text { Debu yang } \\
\text { akan otomatis } \\
\text { refresh setiap } 5 \\
\text { detik } \\
\end{array}$ & Berhasil \\
\hline $\begin{array}{c}\text { Pengujian } \\
\text { tampilan grafik } \\
\text { Suhu }\end{array}$ & $\begin{array}{c}\text { Mengaktifkan } \\
\text { generator pada } \\
\text { database, kemudian } \\
\text { memilih Suhu pada } \\
\text { halaman detail } \\
\text { sensor }\end{array}$ & $\begin{array}{l}\text { Menampilkan } \\
\text { grafik Suhu } \\
\text { yang akan } \\
\text { otomatis } \\
\text { refresh setiap 5 } \\
\text { detik } \\
\end{array}$ & Berhasil \\
\hline $\begin{array}{c}\text { Pengujian } \\
\text { tampilan grafik } \\
\text { Kelembaban } \\
\text { Udara }\end{array}$ & $\begin{array}{c}\text { Mengaktifkan } \\
\text { generator pada } \\
\text { database, kemudian } \\
\text { memilih } \\
\text { Kelembaban Udara } \\
\text { pada halaman detail } \\
\text { sensor } \\
\end{array}$ & $\begin{array}{c}\text { Menampilkan } \\
\text { grafik } \\
\text { Kelembaban } \\
\text { Udara yang } \\
\text { akan otomatis } \\
\text { refresh setiap 5 } \\
\text { detik } \\
\end{array}$ & Berhasil \\
\hline
\end{tabular}




\begin{tabular}{|c|c|c|c|}
\hline $\begin{array}{c}\text { Pengujian } \\
\text { tampilan grafik } \\
\text { Intensitas } \\
\text { Cahaya }\end{array}$ & $\begin{array}{c}\text { Mengaktifkan } \\
\text { generator } \text { pada } \\
\text { database, kemudian } \\
\text { memilih Intensitas } \\
\text { Cahaya pada } \\
\text { halaman detail } \\
\text { sensor }\end{array}$ & $\begin{array}{c}\text { Menampilkan } \\
\text { grafik Intensitas } \\
\text { Cahaya yang } \\
\text { akan otomatis } \\
\text { refresh setiap } 5 \\
\text { detik }\end{array}$ & Berhasil \\
\hline $\begin{array}{c}\text { Pengujian } \\
\text { tampilan grafik } \\
\text { Kelembaban } \\
\text { Tanah }\end{array}$ & $\begin{array}{c}\text { Mengaktifkan } \\
\text { generator pada } \\
\text { database, kemudian } \\
\text { memilih } \\
\text { Kelembaban Tanah } \\
\text { pada halaman detail } \\
\text { sensor }\end{array}$ & $\begin{array}{c}\text { Menampilkan } \\
\text { grafik } \\
\text { Kelembaban } \\
\text { Tanah yang } \\
\text { akan otomatis } \\
\text { refresh setiap 5 } \\
\text { detik }\end{array}$ & Berhasil \\
\hline $\begin{array}{c}\text { Pengujian } \\
\text { tampilan grafik } \\
\text { berdasarkan } \\
\text { waktu } 1 \text { jam, } 1 \\
\text { hari dan } 1 \\
\text { minggu } \\
\end{array}$ & $\begin{array}{c}\text { Memilih waktu } \\
\text { untuk menampilkan } \\
\text { grafik yang berada } \\
\text { pada halaman detail } \\
\text { sensor. }\end{array}$ & $\begin{array}{l}\text { Menampilkan } \\
\text { grafik } \\
\text { berdasarkan } \\
\text { waktu. }\end{array}$ & Berhasil \\
\hline
\end{tabular}

Tabel 6. Pengujian buat laporan

\begin{tabular}{|c|c|c|c|}
\hline $\begin{array}{c}\text { Nama } \\
\text { Pengujian }\end{array}$ & $\begin{array}{c}\text { Bentuk } \\
\text { Pengujian }\end{array}$ & $\begin{array}{c}\text { Hasil yang } \\
\text { Diharapkan }\end{array}$ & $\begin{array}{c}\text { Hasil } \\
\text { Pengujian }\end{array}$ \\
\hline $\begin{array}{c}\text { Pengujian } \\
\text { mencetak } \\
\text { laporan sesuai } \\
\text { tanggal }\end{array}$ & $\begin{array}{c}\text { Mengisi tanggal } \\
\text { yang diinginkan } \\
\text { untuk mencetak } \\
\text { laporan lalu klik } \\
\text { tombol buat } \\
\text { laporan }\end{array}$ & $\begin{array}{c}\text { Laporan terunduh } \\
\text { dan hasil laporan } \\
\text { berupa grafik sesuai } \\
\text { tanggal, yang } \\
\text { dicetak pada } \\
\text { Microsoft Excel. }\end{array}$ & \\
\hline Pengujian & $\begin{array}{c}\text { Mengisi tanggal } \\
\text { mencetak } \\
\text { yang tidak }\end{array}$ & $\begin{array}{c}\text { Laporan tidak } \\
\text { tercetak, halaman }\end{array}$ & Berhasil \\
laporan yang & terdapat datanya & melakukan refresh & \\
tidak ada pada & pada database & untuk memasukkan \\
database & & tanggal. & \\
\hline
\end{tabular}

Tabel 7. Pengujian halaman daftar sensor

\begin{tabular}{|c|c|c|c|}
\hline $\begin{array}{c}\text { Nama } \\
\text { Pengujian }\end{array}$ & $\begin{array}{c}\text { Bentuk } \\
\text { Pengujian }\end{array}$ & Hasil yang Diharapkan & $\begin{array}{c}\text { Hasil } \\
\text { Pengujian }\end{array}$ \\
\hline $\begin{array}{c}\text { Pengujian } \\
\text { tampilan } \\
\text { daftar sensor }\end{array}$ & $\begin{array}{c}\text { Memilih } \\
\text { menu daftar } \\
\text { sensor pada } \\
\text { menubar }\end{array}$ & $\begin{array}{c}\text { Menampilkan tampilan } \\
\text { daftar sensor yang } \\
\text { berada pada basis data } \\
\text { sensor }\end{array}$ & Berhasil \\
\hline $\begin{array}{c}\text { Pengujian } \\
\text { tombol } \\
\text { tambah } \\
\text { sensor }\end{array}$ & $\begin{array}{c}\text { Menekan } \\
\text { tombol } \\
\text { Tambah } \\
\text { Sensor }\end{array}$ & $\begin{array}{c}\text { Menampilkan form } \\
\text { tambah data sensor }\end{array}$ & Berhasil \\
\hline $\begin{array}{c}\text { Pengujian } \\
\text { tombol ubah }\end{array}$ & $\begin{array}{c}\text { Menekan } \\
\text { tombol Ubah }\end{array}$ & $\begin{array}{c}\text { Menampilkan pop up } \\
\text { ubah data sensor }\end{array}$ & Berhasil \\
\hline $\begin{array}{c}\text { Pengujian } \\
\text { tombol buka } \\
\text { peta }\end{array}$ & $\begin{array}{c}\text { Menekan } \\
\text { tombol Buka } \\
\text { Peta }\end{array}$ & $\begin{array}{c}\text { Menampilkan halaman } \\
\text { peta }\end{array}$ & Berhasil \\
\hline $\begin{array}{c}\text { Pengujian } \\
\text { tombol hapus }\end{array}$ & $\begin{array}{c}\text { Menekan } \\
\text { tombol Hapus }\end{array}$ & $\begin{array}{c}\text { Menampilkan alert } \\
\text { hapus, jika klik OK } \\
\text { maka data akan terhapus } \\
\text { dari basis data }\end{array}$ & Berhasil \\
& & & \\
\hline
\end{tabular}

Tabel 8. Pengujian halaman peta

\begin{tabular}{|c|c|c|c|}
\hline $\begin{array}{c}\text { Nama } \\
\text { Pengujian }\end{array}$ & $\begin{array}{c}\text { Bentuk } \\
\text { Pengujian }\end{array}$ & Hasil yang Diharapkan & $\begin{array}{c}\text { Hasil } \\
\text { Pengujian }\end{array}$ \\
\hline $\begin{array}{c}\text { Pengujian } \\
\text { menu } \\
\text { peta }\end{array}$ & $\begin{array}{c}\text { Memilih menu } \\
\text { Peta pada } \\
\text { menubar }\end{array}$ & $\begin{array}{c}\text { Menampilkan halaman } \\
\text { peta }\end{array}$ & Berhasil \\
\hline $\begin{array}{c}\text { Pengujian } \\
\text { node } \\
\text { pada peta }\end{array}$ & $\begin{array}{c}\text { Menekan } \text { node } \\
\text { yang berada } \\
\text { pada peta }\end{array}$ & $\begin{array}{c}\text { Menampilkan data secara } \\
\text { realtime tanpa } \\
\text { melakukan refresh } \\
\text { halaman pada } \text { node yang } \\
\text { ditekan dan peta otomatis } \\
\text { diperbesar }\end{array}$ & Berhasil \\
& & & \\
\hline
\end{tabular}

Tabel 9. Pengujian halaman tentang

\begin{tabular}{|c|c|c|c|}
\hline $\begin{array}{c}\text { Nama } \\
\text { Pengujian }\end{array}$ & $\begin{array}{c}\text { Bentuk } \\
\text { Pengujian }\end{array}$ & $\begin{array}{l}\text { Hasil yang } \\
\text { Diharapkan }\end{array}$ & $\begin{array}{c}\text { Hasil } \\
\text { Pengujian }\end{array}$ \\
\hline $\begin{array}{c}\text { Pengujian } \\
\text { menu tentang }\end{array}$ & $\begin{array}{l}\text { Memilih menu } \\
\text { Tentang pada } \\
\text { menubar }\end{array}$ & $\begin{array}{c}\text { Menampilkan } \\
\text { halaman tentang }\end{array}$ & Berhasil \\
\hline
\end{tabular}

\section{KESIMPULAN DAN SARAN}

\section{A. Kesimpulan}

Dari hasil pengujian dan analisis Sistem Informasi Kampus Hijau Berbasis Web dapat disimpulkan beberapa hal yaitu, Sistem Informasi Kampus Hijau telah berhasil menampilkan data sensor dari beberapa node sensor secara realtime. Sistem Informasi Kampus Hijau telah berhasil menampilkan data sensor berdasarkan waktu dalam bentuk grafik secara realtime.Sistem Informasi Kampus Hijau telah berhasil menampilkan peta lokasi dengan data pada setiap node secara realtime. Data di Sistem Informasi Kampus Hijau telah berhasil dicetak pada Microsoft Excel. Sistem Informasi Kampus Hijau dapat mengelola daftar sensor yang terhubung. Berdasarkan hasil pengujian Sistem Informasi Kampus Hijau dengan menggunakan blackbox, seluruh fungsi menu yang ada dalam sistem telah berhasil dan berjalan sesuai dengan fungsinya masing-masing.

B. Saran

Berdasarkan pengujian terhadap sistem informasi kampus hijau yang telah dibuat, dapat diberikan beberapa saran yaitu, Perlu dilakukan penambahan backup server agar data dapat dicadangkan untuk menanggulangi jika terjadi kehilangan maupun kerusakan data untuk mendukung keterjaminan data pada sistem informasi. Perlu dilakukan pengembangan sistem lebih lanjut agar tidak hanya dapat menampilkan data sensor lingkungan tetapi juga menampilkan halaman berita yang terkait dengan kampus hijau di Universitas Diponegoro. Perlu dilakukan pengembangan grafik pada sistem, agar grafik tidak diperbarui saat kondisi sensor dideteksi tidak aktif. Perlu dilakukan penelitian lebih lanjut untuk mengambangkan buat laporan pada sistem agar dapat mencetak data lebih dari 1 hari.

\section{DAFTAR PUSTAKA}

[1] Universitas Indonesia, "Overall Ranking 2015". http://greenmetric.ui.ac.id/ overall-ranking-2015/. Diakses pada tanggal 14 Februari 2016.

[2] Universitas Indonesia, "Sepeda Kuning". http://www.ui.ac.id/layanan/ sepeda-kuning.html. Diakses pada tanggal 14 Februari 2016.

[3] Jawa Pos. 6 September, 2015. Pemantau Kualitas Udara Cuma Dua, halaman 30.

[4] A.S Rosa dan Salahuddin M, 2011. Modul Pembelajaran Rekayasa Perangkat Lunak (Terstruktur dan Berorientasi Objek), Modula, Bandung.

[5] Fadilah Wati, Siska, Sistem Informasi Penjualan Dan Pemesanan Layanan Berbasis Web Dan Sms Gateway Di Pet Shop "Petzone", Skripsi S-1 Universitas Diponegoro, Semarang, 2013.

[6] Hidayatullah, M. Nur. Penerapan Metodologi Waterfall dalam Pengembangan Sistem Informasi Akademik Universitas Negeri Surabaya. http://jenengku-dayat.mhs.narotama.ac.id/files/2013/ 10/makalah-analisis-SSI.pdf. Diakses pada tanggal 21 Februari 2016. 